\title{
The role of modal parameters uncertainty estimation in automated modal identification, modal tracking and data normalization ${ }^{1}$
}

\author{
Sérgio Pereira ${ }^{a}{ }^{*}$, Edwin Reynders ${ }^{b}$, Filipe Magalhães ${ }^{a}$, Álvaro Cunha $^{a}$, Jorge P. Gomes $^{c}$ \\ a Construct-ViBest, Faculty of Engineering (FEUP), University of Porto, Rua Dr. Roberto Frias, 4200-465 Porto, Portugal \\ b University of Leuven (KU Leuven), Department of Civil Engineering, Kasteelpark Arenberg 40, B-3001 Leuven, Belgium \\ ${ }^{\mathrm{C}}$ National Laboratory for Civil Engineering (LNEC), Av. do Brasil 101, 1700-066 Lisboa, Portugal
}

\begin{abstract}
During the last decade, many vibration-based structural health monitoring systems have been successfully implemented in different structures such as bridges, towers, stadia and wind turbines, with the aim of studying the structure dynamics and its evolution over time, eventually detecting the occurrence of novel structural behaviour that may indicate the presence of damage.

Such vibration-based monitoring systems generally rely on the identification of modal properties, which are then used as monitoring features. Therefore, from operational modal analysis to the tracking of those features and finally to data normalization, many processing steps occur that depend on the accuracy of the identified modal properties. Thus, the estimation of the uncertainties associated with the identified modal properties increases the robustness of this process.

In this context, data obtained from the continuous dynamic monitoring of a concrete arch dam has been used to evaluate the gains of quantifying the uncertainties of modal properties, evaluating in particular the effect of taking these uncertainties into consideration when performing automated operational modal analysis, modal tracking and data normalization. Nevertheless, it is observed that the most significant gains of considering estimates uncertainties occur when these quantities are used for removing outliers during modal tracking.
\end{abstract}

Keywords: dam monitoring, operational modal analysis, uncertainties in modal properties, modal tracking.

\footnotetext{
${ }^{1}$ Postprint submitted to Engineering Structures Published version: S. Pereira, E. Reynders, F. Magalhães, Á. Cunha, and J. Gomes. The role of modal parameters uncertainty estimation in automated modal identification, modal tracking and data normalization. Engineering Structures, 224(111208):1-13, 2020.

https://doi.org/10.1016/j.engstruct.2020.111208
} 


\section{Introduction}

Modal analysis provides important information about the global structural behaviour that can be very useful in the monitoring of the structure health condition, complementing the information that can be gathered from other destructive and non-destructive types of testing, inspection and monitoring. Furthermore, the identification of modal properties may play an important role during all the stages of a structure lifecycle, from construction to commissioning stages, as well as during operation service and rehabilitation works [1], through the validation of structural design assumptions, the calibration or updating of models and the implementation of continuous monitoring systems [2].

Integrated monitoring systems considering real-time data are very important to the long-term management of large civil infrastructures [3] [4] [5]. Structural health-monitoring systems were mainly associated with static data in the past, but vibration-based systems have already been successfully implemented in many different applications and are nowadays very common in structures such as bridges [6] [7] [8] [9] [10] [11], wind turbines [12] [13] [14], stadia [15], bell-towers [16] [17] [18], or concrete dams [19] [20] [21].

Such vibration-based health monitoring systems rely on automated operational modal analysis to continuously identify the structure's modal properties, which are then used as monitoring features to evaluate the structures health condition evolution over time and the eventual emergence of novel structural behaviour. From operational modal analysis [22] [23] [24] to the tracking of these features [25] [26], there are many processing steps [27] where errors can occur and be propagated. Therefore, the calculation of the uncertainties associated with the identified modal properties in each single setup may act as an important tool in this process, helping to quantify confidence levels and to eliminate misidentifications of modal properties, thus creating more robust and reliable monitoring databases. To test the influence of the consideration of the uncertainties associated with modal properties in vibration-based testing and monitoring, the data obtained during two years of continuous monitoring of Baixo Sabor arch dam is used.

This paper first introduces the theoretical background related to the sources and quantification of the uncertainty associated with modal properties and to the techniques used for automated operational modal analysis in the present application. Then, a brief description of the dynamic monitoring system installed in Baixo Sabor arch dam is presented, followed by the identification of modal properties and respective uncertainties. Afterwards, the modal properties of the structure are tracked during two years and the effect of the consideration of their uncertainties in the tracking procedure is presented. Finally, the possibility of improving the mitigation of the effects of operational and environmental conditions on natural frequencies through the employment of uncertainties in the fitting of regression models is investigated.

\section{Tools for data processing}

\subsection{Modal parameters uncertainty estimation}

Modal parameters of a structure, estimated from ambient vibration measurements using state of art identification methods [28] [29] [30] [31], are always subject to bias and variance errors. Since identified modal characteristics are quite often used for calibration and validation of dynamic structural models, for structural control or structural health monitoring it becomes important to analyse the accuracy associated with 
estimated parameters. Errors introduced in the identification process may be due to several reasons [32]. For instance: the use of a finite number of data samples; the inputs may not be a white noise; nonlinear distortions may be present in the data because of material or geometrical nonlinearities; non-stationary nature of excitations or structures, activated by external factors such as temperature or wind; analogue and/or digital filters introducing spurious poles; human-induced errors.

Depending both on the identification method used and on the structure characteristics, each of the previous error causes may gain relevance over the others and even different causes that were not mentioned may arise. Both the physical part of the problem, more strongly associated with the data collection, and the processing part, strictly related with the identification procedure, must be conducted with extreme care, in order to reduce the number of error sources and to mitigate the effects of those that cannot be completely suppressed.

To mitigate bias errors, stabilization diagrams [33] [34] [35] [36] [37] [38] used when parametric methods are applied are an important tool. However, unlike bias errors, which can often be mitigated to a large extent, variance errors can only be estimated, they cannot be removed. In [32] [39], a detailed sensitivity analysis of the reference-based covariance-driven stochastic subspace identification method (SSI-Cov) yielded a novel expression for the covariance of the identification errors of the modal parameters estimates, allowing the estimation of uncertainty bounds. A computationally faster version of this algorithm [40] was later developed along with a multi-order extended implementation that allows the calculation of uncertainty bounds for all elements of a stabilization diagram. This second version was integrated on the available routines for automated operational modal analysis to obtain standard deviation values associated with all the modal estimates. An application example is presented in [41] using ambient vibration data of the Z24 Bridge, and full validation of the method is carried out in [42] with two application examples.

Other methods for the calculation of uncertainties and confidence intervals, related to other identification methods than SSI-Cov, can be found in [43], [44], [45], [46], [47], [48], [49], [50] and [51] though these are not explored in the present work.

\subsection{Automated operational modal analysis and modal tracking}

Automated operational modal analysis is crucial in the context of continuous dynamic monitoring in order to process more easily the enormous amount of data produced, and to obtain results in real-time. In this application, the automation of operational modal analysis is achieved through the combination of the SSICov method with a routine based on cluster analysis.

After the application of the SSI-Cov method to each time series of accelerations and after the construction of stabilization diagrams, the methodology based on a hierarchical clustering algorithm proposed in [52] is used to group poles with similar modal properties, thus producing groups with high internal (within-cluster) homogeneity and high external (between-cluster) heterogeneity. The similarity between poles is measured using a metric that depends on the relative differences between natural frequencies and consistency of mode shapes. Therefore, considering the mentioned metric, short distances between two poles mean that they represent similar frequencies and modal configurations and that they probably represent the same vibration mode, so they should be included in the same cluster. 
Then, a predefined number of different clusters are obtained from the application of hierarchical cluster analysis, corresponding to both physical and numerical modes. The final modal estimates associated with the dataset under analysis are defined as the mean values of the poles included in the clusters with a larger number of elements. The modal estimates identified in each setup are compared with a set of reference values, which were obtained from selected datasets with very clear stabilization diagrams. Each new set of modal properties is only accepted as a physical mode if the MAC (Modal Assurance Criterion) [53] between the estimated mode shape and the reference mode shape is higher than a predetermined threshold and the variation between their frequency values is lower than a second threshold. For modes between the first and the fifth, values of 0.90 and $10 \%$ were respectively used as MAC and frequency variation thresholds. In the case of the sixth mode, since several estimates presented MAC values (relative to the reference) between 0.55 and 0.75 , lower thresholds had to be used, respectively of 0.55 and $5 \%$.

\subsection{Effect of modal properties uncertainties on modal tracking}

Using the methodology presented in the previous section for automated operational modal analysis, a group of clusters is obtained after the application of SSI-Cov to 30-minute datasets of recorded accelerations. Moreover, each cluster is composed of a group of poles and, if the version of SSI-Cov presented in [32] and [40] is used, besides the three regular quantities obtained from the common application of SSI-Cov, two more are obtained with this version, thus five different quantities are associated with each pole:

- Natural frequency (f [Hz]);

- Damping ratio (d [\%]);

- Mode Shape;

- Standard deviation of natural frequency $\left(\mathrm{f}_{\text {std }}[\mathrm{Hz}]\right)$;

- Standard deviation of damping ratio ( $\left.\mathrm{d}_{\mathrm{std}}[\%]\right)$.

With this implementation, it is possible to obtain as well the standard deviations associated with each modal ordinate, which would indicate the uncertainty related to the mode shape. However, this was not considered in this work. Additionally, coefficients of variation may be computed, dividing each standard deviation value by its natural frequency $\left(\mathrm{f}_{\mathrm{cv}}\right)$ or damping ratio $\left(\mathrm{d}_{\mathrm{cv}}\right)$. In the end, the estimates of modal properties and respective standard deviation values are calculated as the mean value of all the poles integrating the cluster, eventually disregarding estimates with high uncertainty.

An example using real data from the dynamic monitoring system of Baixo Sabor is presented in Table 1, comprehending five poles, which for the purpose of this example were selected from all the poles belonging to the same cluster, thus resulting from the same set of 30 minutes acceleration time series. Only five poles were used in order to keep the example as simple as possible, however, any other five poles could have been selected or even the entire cluster could have been used.

Information about the data acquisition and processing used is presented in section 3.1. Most of the five poles present natural frequencies close to $3.52 \mathrm{~Hz}$, and damping ratios around $1.5 \%$. It is worth noting that the frequency value of pole 3 , the only one in the group closer to 3.51 than to $3.52 \mathrm{~Hz}$, shows the highest standard deviation, indicating that higher uncertainty is associated with this pole. The same is observed with the 
standard deviation of its damping ratio, which is so high that it leads to a coefficient of variation of $101.7 \%$. In this sense, the estimates of modal properties for this cluster were calculated considering both the mean of the five poles and the mean of four poles, excluding pole 3. Even if small differences were obtained, it is worth pointing out that the uncertainty associated with the modal properties was minimized in the second case, which gives the analyst more confidence in the obtained results and prospects better chances of successfully building models that accurately represent the structure's behaviour.

Finally, it is important to emphasize that all the poles used in this example were obtained using the same setup of time series but considering different model orders.

Table 1 - Example of poles properties of a given cluster

\begin{tabular}{ccccccc}
\hline Pole & $\mathrm{f}[\mathrm{Hz}]$ & $\mathrm{f}_{\text {std }}[\mathrm{Hz}]$ & $\mathrm{f}_{\mathrm{cv}}[\%]$ & $\mathrm{d}[\%]$ & $\mathrm{d}_{\text {std }}[\%]$ & $\mathrm{d}_{\mathrm{cv}}[\%]$ \\
\hline 1 & 3.522 & 0.0041 & 0.117 & 1.488 & 0.110 & 7.4 \\
2 & 3.521 & 0.0053 & 0.152 & 1.503 & 0.229 & 15.2 \\
3 & 3.513 & 0.0419 & 1.194 & 1.540 & 1.566 & 101.7 \\
4 & 3.524 & 0.0086 & 0.245 & 1.624 & 0.335 & 20.6 \\
5 & 3.520 & 0.0113 & 0.321 & 1.585 & 0.500 & 31.6 \\
\hline Mean $_{\text {all }}$ & 3.520 & 0.0143 & 0.406 & 1.548 & 0.548 & 35.3 \\
Mean $_{[1,2,4,5]}$ & 3.522 & 0.0073 & 0.209 & 1.550 & 0.294 & 18.7 \\
\hline
\end{tabular}

\section{Continuous dynamic monitoring of Baixo Sabor arch dam}

\subsection{Instrumented dam and monitoring system}

The Baixo Sabor hydroelectric development is located in the northeast of Portugal, in Sabor River, a tributary of Douro River, and has been operating since early 2016. The reservoir is accomplished with a $123 \mathrm{~m}$ high double-curvature arch dam whose crest is $505 \mathrm{~m}$ long. The arch is composed of 32 concrete blocks separated by vertical contraction joints and includes six horizontal visit galleries. The left part of Figure 1 shows an aerial picture of the dam and the reservoir, dated May 2016, after the continuous monitoring of the structure had started.

A vibration-based health monitoring system was installed in the dam in December 2015, right before it officially started operating, with the aim of identifying the dam's dynamic characteristics and their evolution over time, taking into account the variation of ambient and operational conditions, as well as the possible evolution of the materials mechanical properties. The architecture of the dynamic monitoring system installed in the structure was based on the results provided by a forced vibration test performed in January 2015 by the Portuguese National Laboratory for Civil Engineering (LNEC) and by a numerical model developed by the same institution [54].

The continuous dynamic monitoring system consists of 20 uniaxial accelerometers that have been radially disposed in the dam's three upper visit galleries, whose synchronization is achieved using GPS antennas. The right part of Figure 1 shows the position of the accelerometers installed in the dam, marked with red dots in a picture of the structure. The accelerometers used are force balance (FBA ES-U and FBA ES-U2 from kinemetrics) with a dynamic range of $140 \mathrm{~dB}$ and $155 \mathrm{~dB}$, respectively, and a frequency bandwidth that goes 
from DC to $200 \mathrm{~Hz}$, which were configured to measure in the range $-0.25 \mathrm{~g} /+0.25 \mathrm{~g}$, in order to allow the accurate characterization of very low acceleration signals. The dynamic monitoring system is configured to continuously record acceleration time series with a sampling rate of $50 \mathrm{~Hz}$ and a duration of 30 minutes at all instrumented points, thus producing 48 groups of time series per day. Given the low level of the measured signals, time series with 30 minutes of length were considered to provide a good balance between the quality of the estimates and the ability to characterize modal parameters variations over time with adequate time resolution.

The continuously collected data is processed with a monitoring software developed at ViBest/FEUP called DynaMo [55]. Besides backing up the original data samples, this monitoring software performs the preprocessing of the acceleration time series, through trend elimination, filtering and re-sampling to $25 \mathrm{~Hz}$, it characterizes vibration levels and it performs the identification of the dam modal properties through automated operational modal analysis. The continuous and automatic identification of modal parameters is achieved by combining the Covariance Driven Stochastic Subspace Identification method (SSI-Cov) with the routine based on cluster analysis that was described in the previous section. The results obtained between $01 / 12 / 2015$ and 30/11/2017 will be analysed.

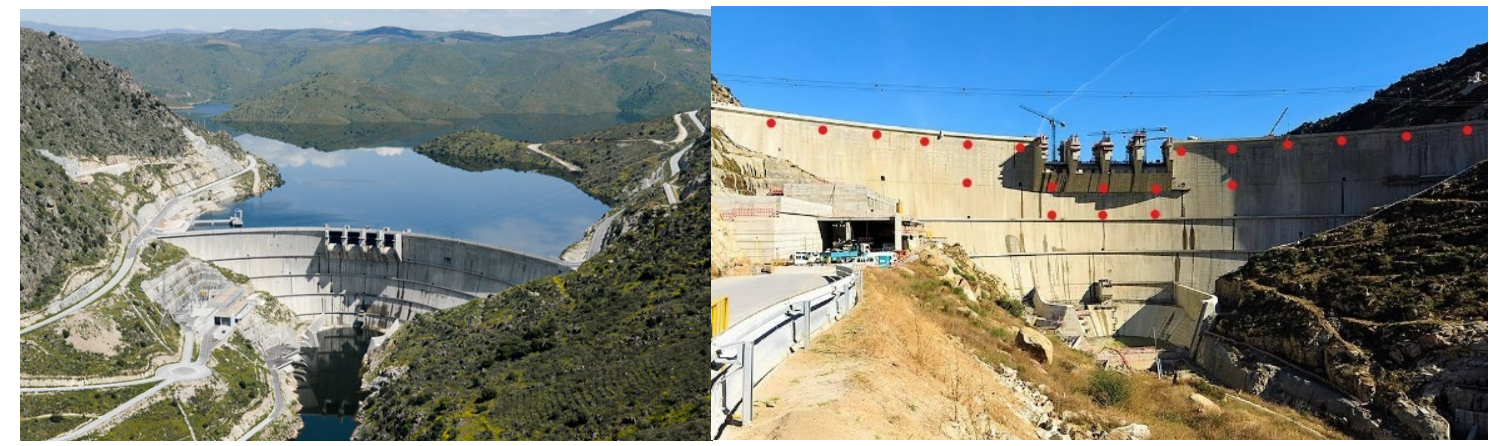

Figure 1 - Baixo Sabor arch dam: a) aerial view (on the left); b) position of accelerometers marked with red dots (on the right) [56]

\subsection{Modal parameters identification with uncertainty quantification}

To automatically track the evolution of the dam's modal properties over time, reference values of natural frequencies and mode shapes are needed. In order to obtain such references and to calibrate the parameters of the routines for automatic identification, the first few setups obtained with the dynamic monitoring system were manually analysed.

In this sense, the first six modes of vibration were identified using the first set of time-series of accelerations recorded on 01/12/2015, between the 00:00 and the 00:30. Natural frequencies, damping values and modal configurations were obtained. The experimentally estimated mode shapes of the six identified modes are presented in Figure 2, using top-view representations produced with Matlab [57]. All the mode shapes are clear and well-defined, with increasing complexity from the first to the sixth mode. Mode shapes are alternatively symmetrical and anti-symmetrical.

The natural frequencies and damping ratios, with respective standard deviation values, identified from the time series of accelerations measured during the first day of monitoring (01/12/2015), between the 00:00 and 
00:30, are resumed in Table 2. It is important to notice that the first six vibration modes are found between 2 and $7 \mathrm{~Hz}$, generally presenting damping ratios between 1.2 and $1.6 \%$ (the fifth mode being the only exception). The standard deviations associated with the natural frequencies of most modes present values around $0.02 \mathrm{~Hz}$, though these values vary from $0.011 \mathrm{~Hz}$ in the case of the second mode to $0.045 \mathrm{~Hz}$ in the case of the fifth mode. As expected, the values of damping ratios present higher uncertainty, and the standard deviations associated with their estimates vary from 0.383 to $0.857 \%$.
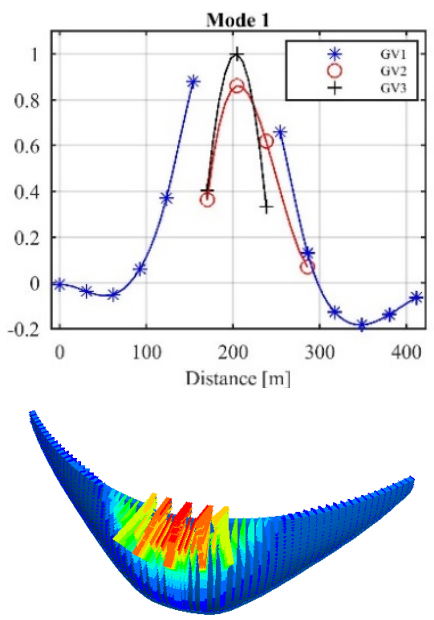

Mode 1
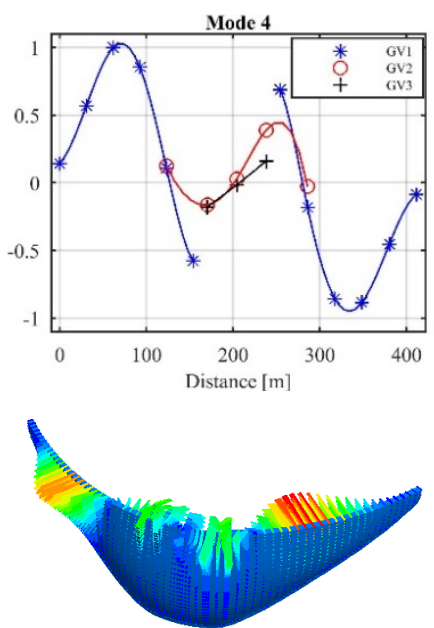

Mode 4
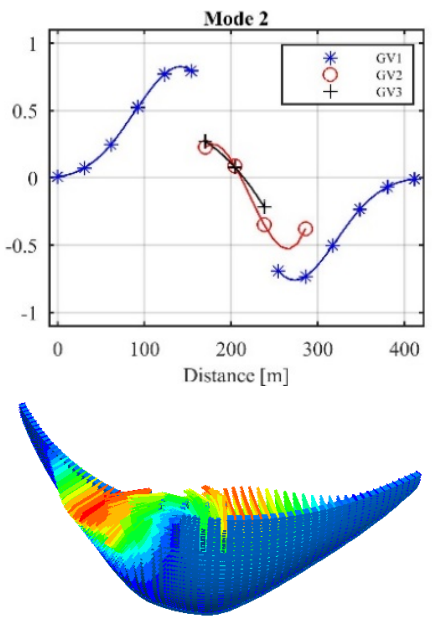

Mode 2
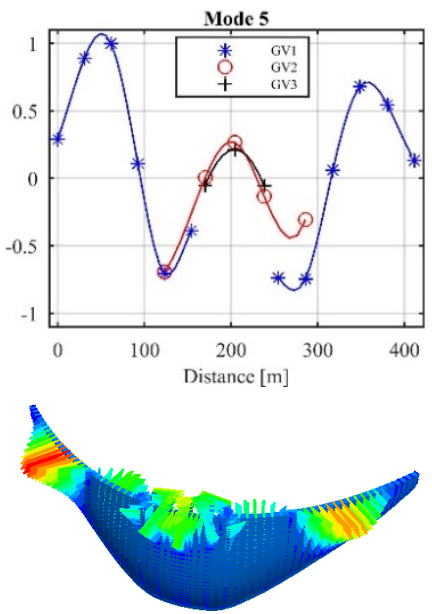

Mode 5
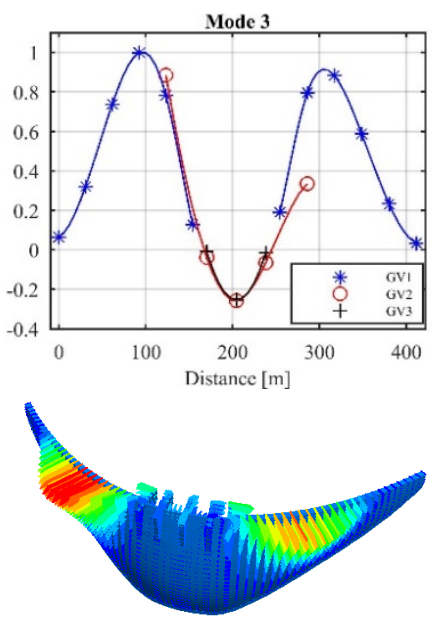

Mode 3
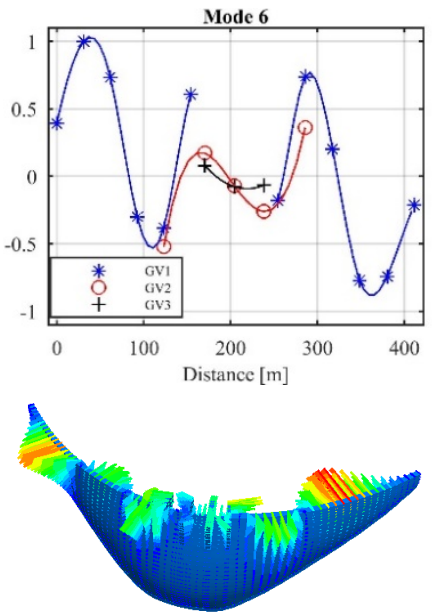

Mode 6

Figure 2 - Mode shapes of the first six modes of Baixo Sabor arch dam: a) top view representations of the experimental modes using the points instrumented at three different heights (see Figure 1); b) three-dimensional representations using numerical results. 
Table 2 - Modal parameters for the structure's first six modes (00:00 - 01/12/2015)

\begin{tabular}{cccccc}
\hline Mode & $\begin{array}{c}f_{\text {mean }} \\
{[\mathrm{Hz}]}\end{array}$ & $\begin{array}{c}f_{\text {std }} \\
{[\mathrm{Hz}]}\end{array}$ & $\begin{array}{c}d_{\text {mean }} \\
{[\%]}\end{array}$ & $\begin{array}{c}d_{\text {std }} \\
{[\%]}\end{array}$ & Description \\
\hline 1 & 2.739 & 0.020 & 1.291 & 0.585 & Symmetric \\
2 & 2.917 & 0.011 & 1.413 & 0.383 & Antisymmetric \\
3 & 3.852 & 0.026 & 1.332 & 0.402 & Symmetric \\
4 & 4.475 & 0.021 & 1.381 & 0.476 & Antisymmetric \\
5 & 5.299 & 0.045 & 2.081 & 0.857 & Symmetric \\
6 & 6.210 & 0.024 & 1.541 & 0.444 & Antisymmetric \\
\hline
\end{tabular}

The standard deviation values obtained for the frequency and damping estimates of a single dataset are important in the sense that they provide a confidence level to the estimates of modal properties. But, as will be demonstrated in the following section, this information is much more useful in the context of the continuous tracking of modal properties

\subsection{Considerations on the sources of misidentifications}

The location of a structure largely conditions the sources and types of vibrations that excite it. Generally, concrete dams are remotely located and thus are subjected to low-intensity vibrations [58]. Such vibrations are mostly due to the wind, both hitting the reservoir surface and the dam's downstream face, to small seismicity, to road traffic when the dam constitutes a link between the two banks of a river, to nearby human activity and to the normal operation of the power plant. In the specific case of Baixo Sabor hydroelectric development, the powerhouse is located downstream, very close to the dam, on the right bank of the river, as can be observed in the left part of Figure 1. As described in [21], the bulk of the vibrations measured by the monitoring system at the dam present low intensity, of the order of micro g, and only when the turbines used for energy production start operating, higher vibration levels are verified.

Therefore, during the vast majority of the time, the dam is either excited solely through ambient vibration (scenario 1) or through ambient vibration plus the vibrations resulting from the operation of the turbines in the power plant (scenario 2). Only on rare occasions, high vibration levels are observed, such as during extreme weather conditions that lead to the opening of the spillway gates.

Since it was known from the preliminary forced vibration test and has been confirmed by the continuous monitoring, that the dam's first vibration mode is not as easily excited as the next few modes, it is necessary to use high model orders (above 100) when applying the SSI-Cov method, to guarantee the identification of this mode. Especially during periods of low vibration intensities, such as those described for scenario 1 . However, the consideration of higher model orders leads to the generation of more spurious modes during the identification processing, which increases the chances of misidentifications. On the other hand, during periods characterized by excitations such as those described for scenario 2, the recorded time-series are polluted by the turbines rotation frequency and its harmonics. These frequencies may be mistakenly confused as vibration modes by the automatic processing routines. Moreover, in some cases, when the frequency of a 
vibration mode is very close to the frequency of a harmonic, the identification method may not be able to separate the two for low model orders, thus introducing a bias in the results. In the colour map presented in Figure 3, thin and well-defined red lines present at frequencies $3.57 \mathrm{~Hz}$ and $7.14 \mathrm{~Hz}$ correspond to the turbine rotation frequency and its first multiple, clearly showing periods of turbine operation. Additionally, other machinery frequently pollutes the data with intense frequency contributions around $6 \mathrm{~Hz}$.

Since the physical phenomena that enhance the occurrence of identification errors have been presented, the next section is dedicated to the minimization of the occurrence of such misidentifications and their propagation, through the consideration of estimates uncertainties in the identification and tracking processes.

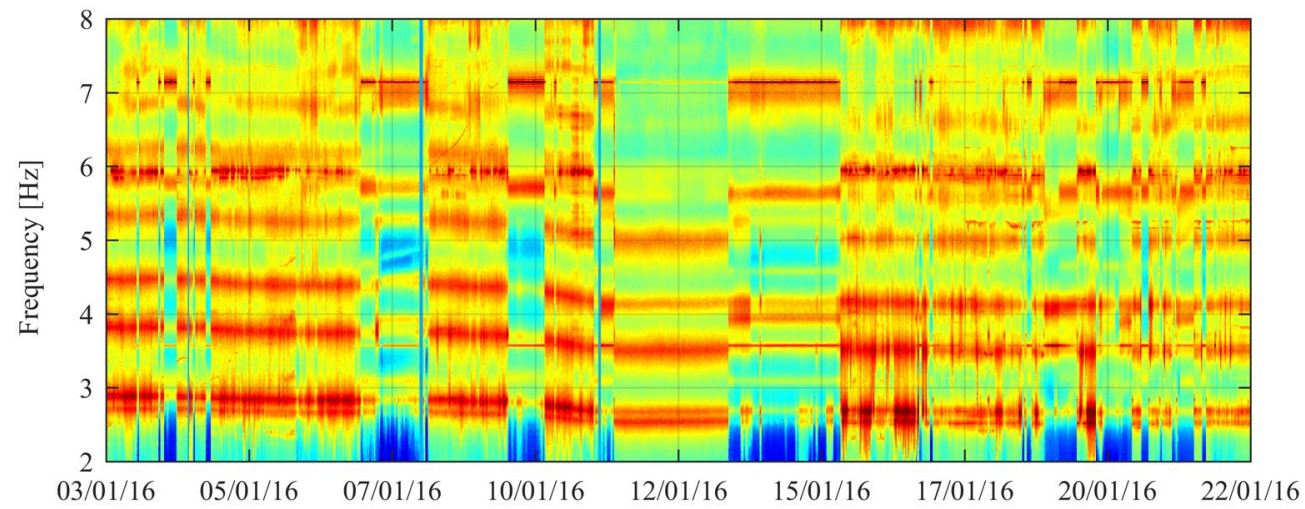

Figure 3 - Colour map with the frequency evolution between 03/01/2016 and 22/01/2016.

\section{Using uncertainties on modal tracking}

The methodology for modal tracking presented in section 2 was applied to two years of data continuously collected by the Baixo Sabor dam dynamic monitoring system between 01/12/2015 and 30/11/2017 and the structure first six vibration modes were tracked. The evolution of the natural frequencies of the dam's first six modes is represented over time in Figure 4, each mode being represented by a different colour, whereas Figure 5 presents the evolution of the six modal damping ratios during the same period, using the same colour system.

Since 48 daily datasets were considered during these 2 years of monitoring, the tracked modal properties show daily and seasonal variability. On the one hand, the seasonal variation, which is due to operational and environmental conditions (essentially reservoir water level and structure temperature), is dominant on natural frequencies time evolution, while on the other hand, higher daily scatter is observed with damping estimates, masking eventual seasonal variations. A useful procedure to observe the real trend of damping ratios consists of comparing the evolution of damping considering all available estimates to that of moving averages with different time-lengths, which reduce the dispersion due to uncertainty and thickens the main trend variations due to physical phenomena. 


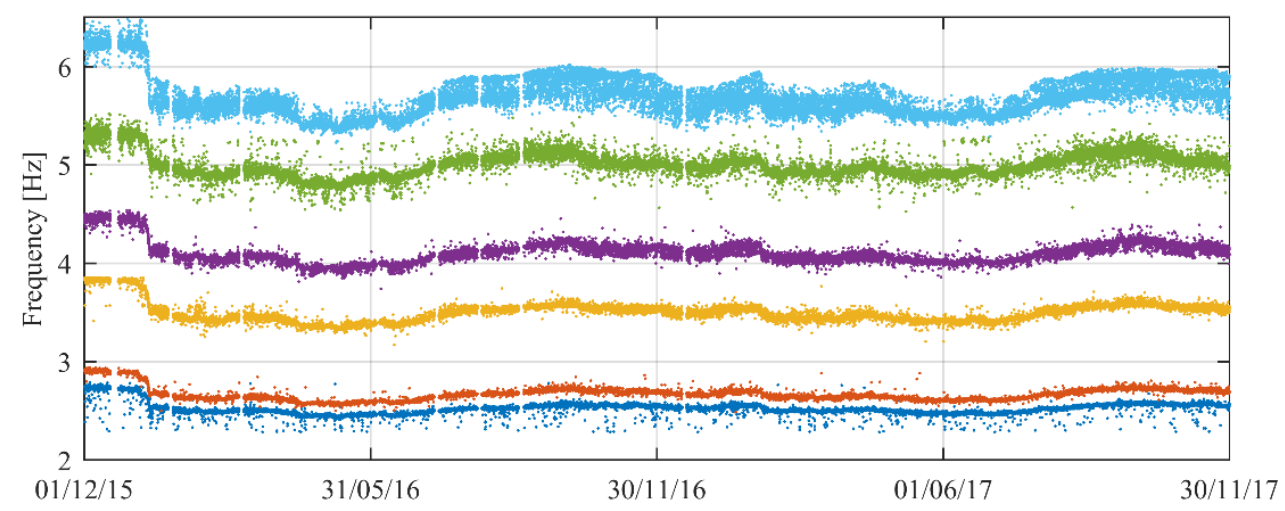

Figure 4 - Evolution of the first six natural frequencies between $01 / 12 / 2015$ and 30/11/2017.

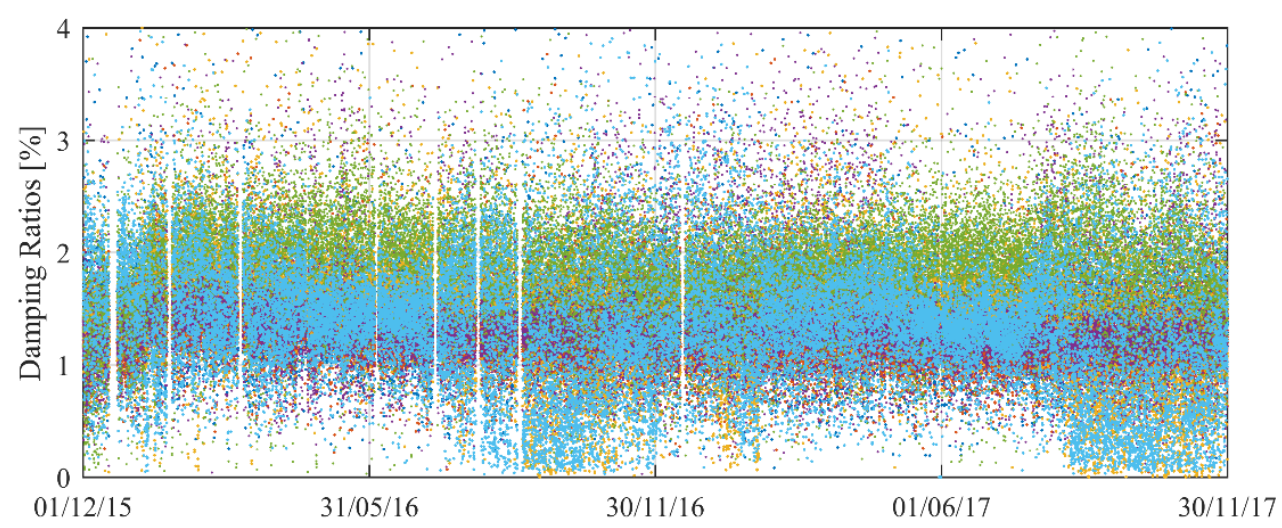

Figure 5 - Evolution of the first six modal damping ratios between $01 / 12 / 2015$ and 30/11/2017.

To evaluate the advantage of considering uncertainties in the algorithm used for modal tracking, the results obtained with two alternative processing methodologies are presented. In Processing A, used as a baseline, the uncertainty of modal estimates was quantified but not included in any step of the tracking algorithm.

In this sense, the natural frequencies and damping ratios obtained with Processing A for the first six modes are represented independently in Figure 6 and Figure 7, to provide a closer evaluation of their evolution over time. The colour of each modal estimate was represented as a linear function of its standard deviation. Therefore, natural frequencies were represented in blue if their standard deviation values were close to $0 \mathrm{~Hz}$, and they were represented in yellow if they were equal or higher than $0.05 \mathrm{~Hz}$. For the modal damping ratios estimates, coefficients of variation were used to choose the colour of each estimate. Thus, damping ratios were represented in blue if their coefficients of variation were close to $0 \%$, and they were represented in yellow if they were equal or higher than $50 \%$.

The value of $0.05 \mathrm{~Hz}$ represents a substantial uncertainty that should not be accepted for the structure under consideration. Furthermore, the $50 \%$ limit for the coefficients of variation results from the consideration that it is not physically possible for damping ratios to be negative. In this sense, assuming a normal distribution and a $95 \%$ confidence interval, the probability of the true value of a damping ratio estimate being negative is limited to $2.5 \%$. 
Figure 6 shows that the frequency estimates of the first modes are generally associated with lower standard deviation values. However, the first five modes show many estimates represented in yellow that clearly diverge from the main tracking line, indicating that considering the uncertainty estimates, the outliers can be eliminated. This is not clear with the sixth mode, though, since due to the lower frequency variation threshold that was used in the automatic tracking of this mode, only a few outliers are observable. The damping ratios of all six modes present as well many estimates represented in yellow, indicating a considerable number of estimates associated to coefficients of variation higher than $50 \%$. Furthermore, besides the normal variability around the mean, mode 3 presents a significant number of estimates with low damping, between 0 and $1 \%$, which do not seem to be season-related. The vast majority of estimates with seemingly abnormal damping values present high coefficients of variation, as indicated by its yellow colour.
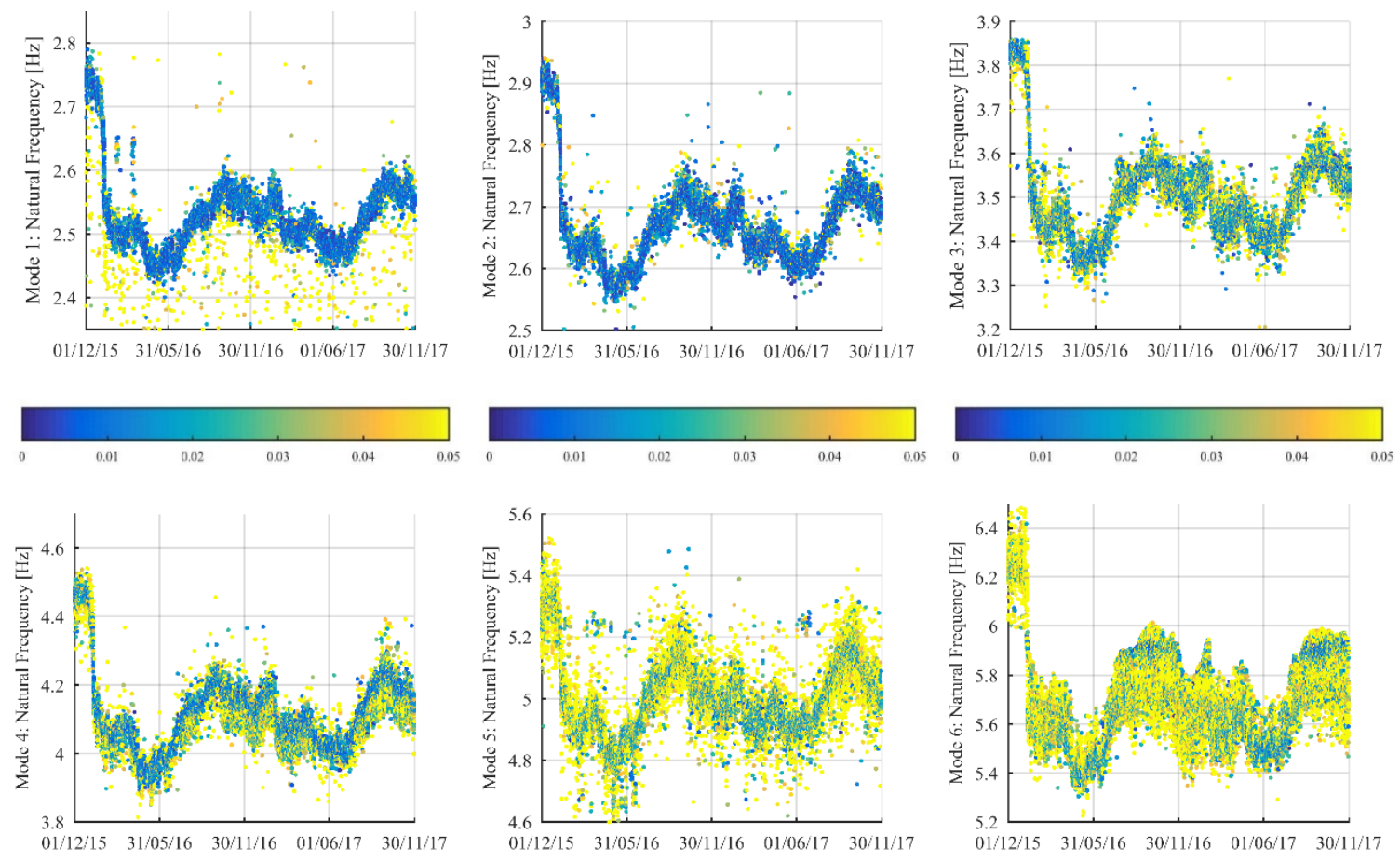

Figure 6 - Natural frequencies with colour as a function of standard deviation (Processing A).
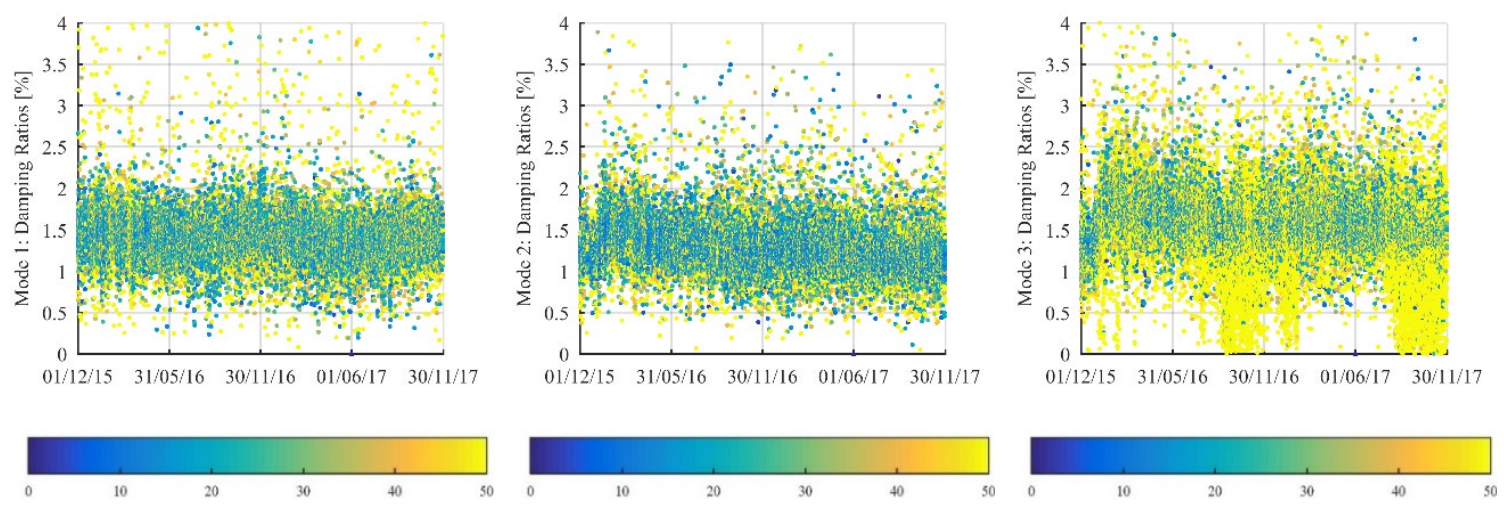

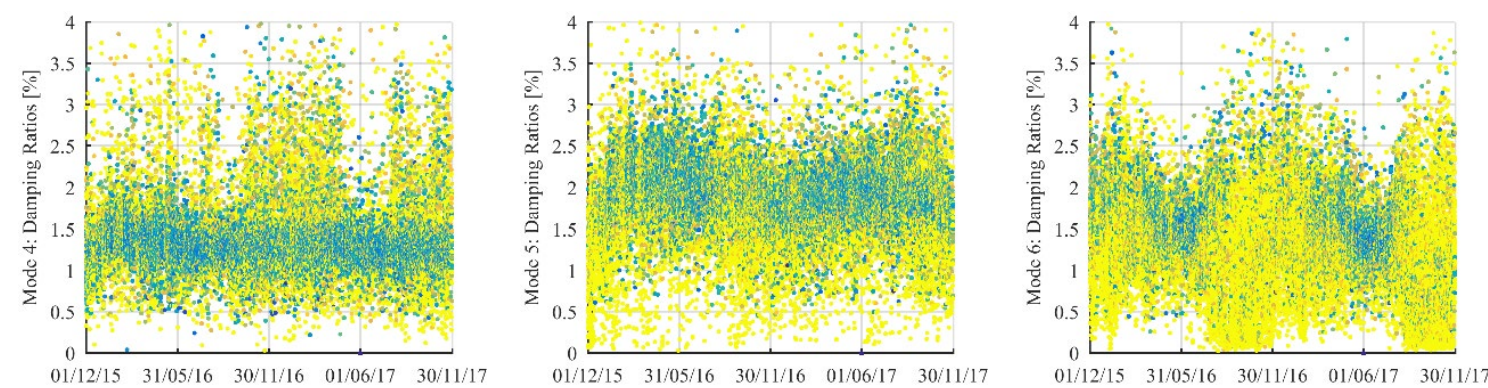

Figure 7 - Damping ratios with colour as a function of the coefficients of variation (Processing A)

After the analysis of the results provided by processing A, a new tracking strategy was put through, yet this time, before the comparison between each new set of modal properties estimates and the previously defined references, all the clusters obtained from the application of SSI-Cov to each 30 minutes time series of accelerations were analysed considering the uncertainties of each pole estimate. This analysis, which will be referenced as Processing B, consisted on the evaluation of standard deviations and, consequently, all the poles whose frequency standard deviation was equal or higher than $0.05 \mathrm{~Hz}$ and all the poles whose damping coefficient of variation was equal or higher than $50 \%$ were eliminated. In conclusion, most clusters became more homogeneous, and many clusters that were composed mainly of poles associated with high standard deviations disappeared. However, the number of setups for which one or more modes were not tracked increased, diminishing the number of successful identifications.

From the perspective of most modes, this strategy turned out to be profitable, and the good results obtained will be presented hereafter. However, in the first stage, in the case of the third mode, it had negative consequences. Figure 8 presents the distribution of frequencies and damping ratios identified for the third mode with Processing B. On the one hand, there is an abnormal number of identifications between 3.55 and $3.60 \mathrm{~Hz}$, and on the other, there is an abnormal number of identifications with damping close to $0 \%$. This indicates that the elimination of poles with higher uncertainty was favourable to a systematic identification of the turbine rotation frequency $(3.57 \mathrm{~Hz})$ as the frequency of mode 3 , increasing the number of misidentifications.
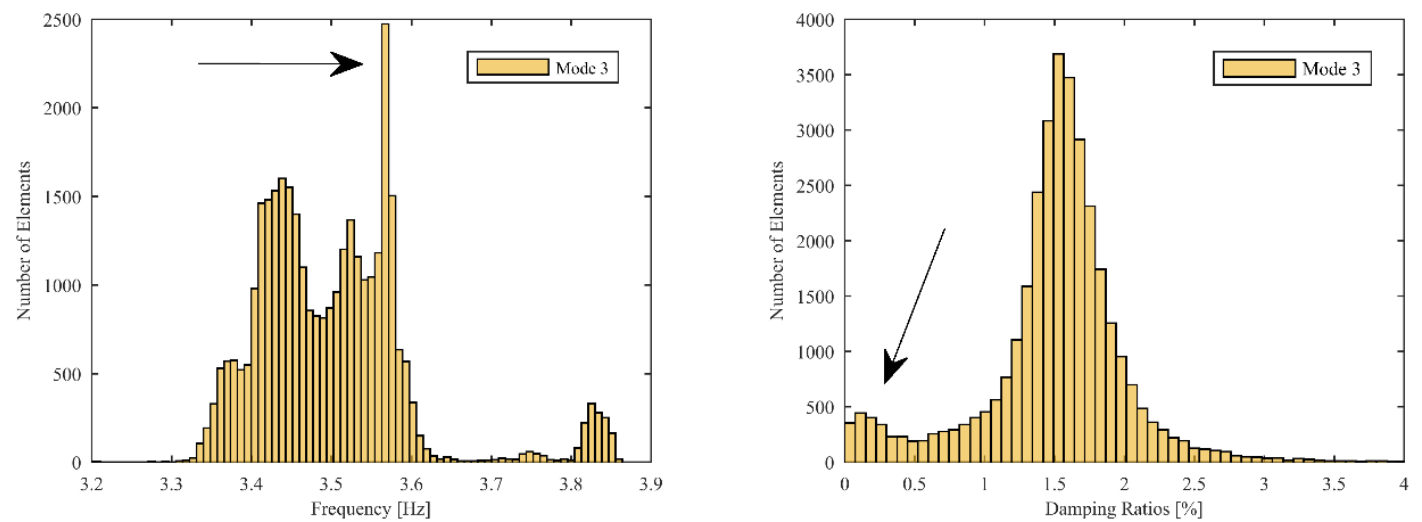

Figure 8 - Histograms of frequency and damping of mode 3 (Processing B), with arrows pointing at anomalies.

In order to minimize the number of times the turbine rotation frequency is identified as mode 3 natural frequency, the characteristics of the estimates associated with this parasite frequency were studied. Thus, 
besides presenting modal damping ratios close to 0 , these estimates systematically present very low standard deviation values for both frequency and damping. In this sense, all the frequency estimates identified for mode 3 which presented frequency standard deviations lower than $0.005 \mathrm{~Hz}$ were represented in yellow in the left part of Figure 9, while all the other frequency estimates were represented in black. The vast majority of yellow points correspond to frequencies very close to $3.57 \mathrm{~Hz}$, therefore associated with the turbine rotation frequency.

In the case of the fourth mode, Processing B did not introduce any kind of bias, on the contrary, though many misidentifications were eliminated, it is still possible to improve the modal tracking of this mode. In this sense, damping estimates with standard deviations higher than $0.5 \%$ were represented in yellow, on the right side of Figure 9, while all the other damping estimates were represented in black. This leads to a figure with a high number of yellow points dispersed all over the damping range but mostly associated with estimates located above from the main damping track. It is worth noting that these outliers present both higher damping values and higher damping standard deviations when compared to the estimates on the main tracking line, therefore it would not be possible to distinguish between the two groups of estimates using the coefficient of variation.
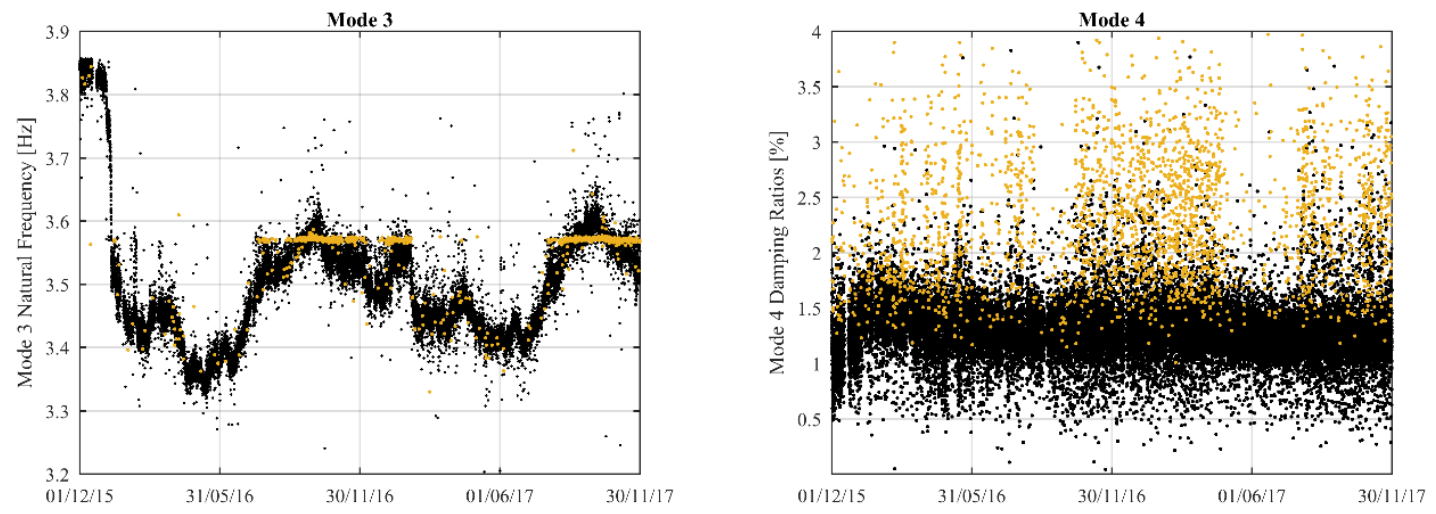

Figure 9 - Misidentifications of the third and fourth modes after Processing B.

Taking into account previous considerations, Processing $\mathrm{C}$ was put through, combining the conditions used in Processing B with the elimination of poles with frequency standard deviations lower than $0.005 \mathrm{~Hz}$, in the range between $3.566 \mathrm{~Hz}$ and $3.576 \mathrm{~Hz}$. Additionally, poles with damping standard deviations higher than 0.5 $\%$ in the range between $3.90 \mathrm{~Hz}$ and $4.60 \mathrm{~Hz}$ were also eliminated. This time, good results were achieved for the six modes. The colour of natural frequency's (Figure 10) and damping (Figure 11) estimates was once again represented as a function of their respective standard deviation values, using the same limits used in Figure 6 and Figure 7. In the case of natural frequency, there are still some outliers in the six modes, but its number reduced considerably. This is clear with the first mode, which though still presenting some outliers below the main frequency track, presents now much fewer outliers than it did initially. Moreover, the six figures generally present darker colours, indicating a significant reduction in the value of standard deviations, thus increasing the confidence level of individual estimates. Though mode 3 still presents a few estimates with high uncertainty, the thin horizontal alignment associated with the turbine frequency is not clearly distinguishable anymore. The general level of accuracy of damping ratios increased as well, though there are still many estimates with high uncertainty. In the case of the third mode, which presented several damping 
ratio estimates with values close to 0 , related to the turbine rotation frequency, the number of low damping estimates decreased considerably. Most of the low damping estimates with high uncertainty that were not eliminated present damping values between 0.5 and $1 \%$, indicating that in some cases the SSI-Cov algorithm was not capable to separate the third mode estimate from the turbine harmonic.
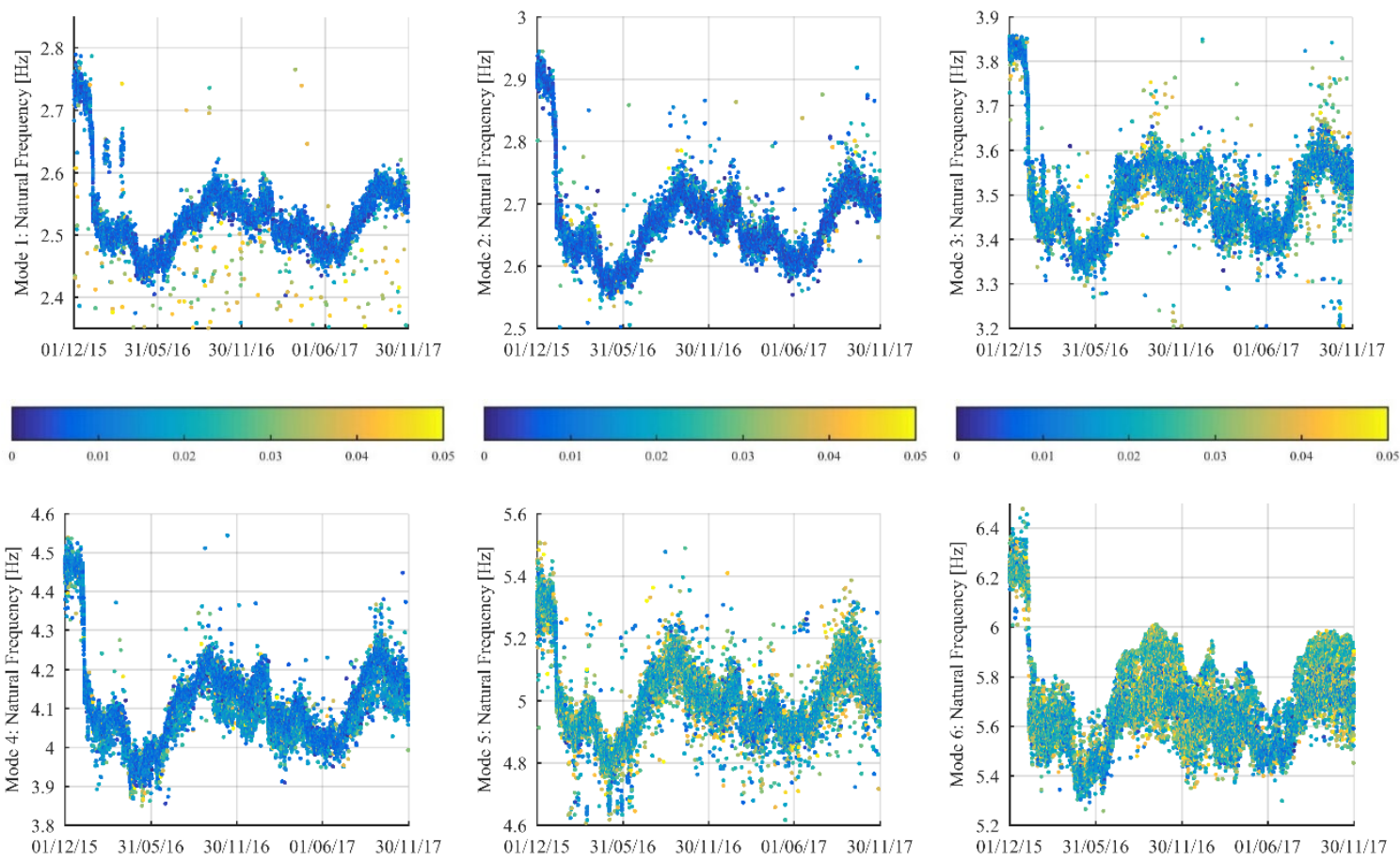

Figure 10 - Natural frequencies with colour as a function of standard deviation (Processing C).
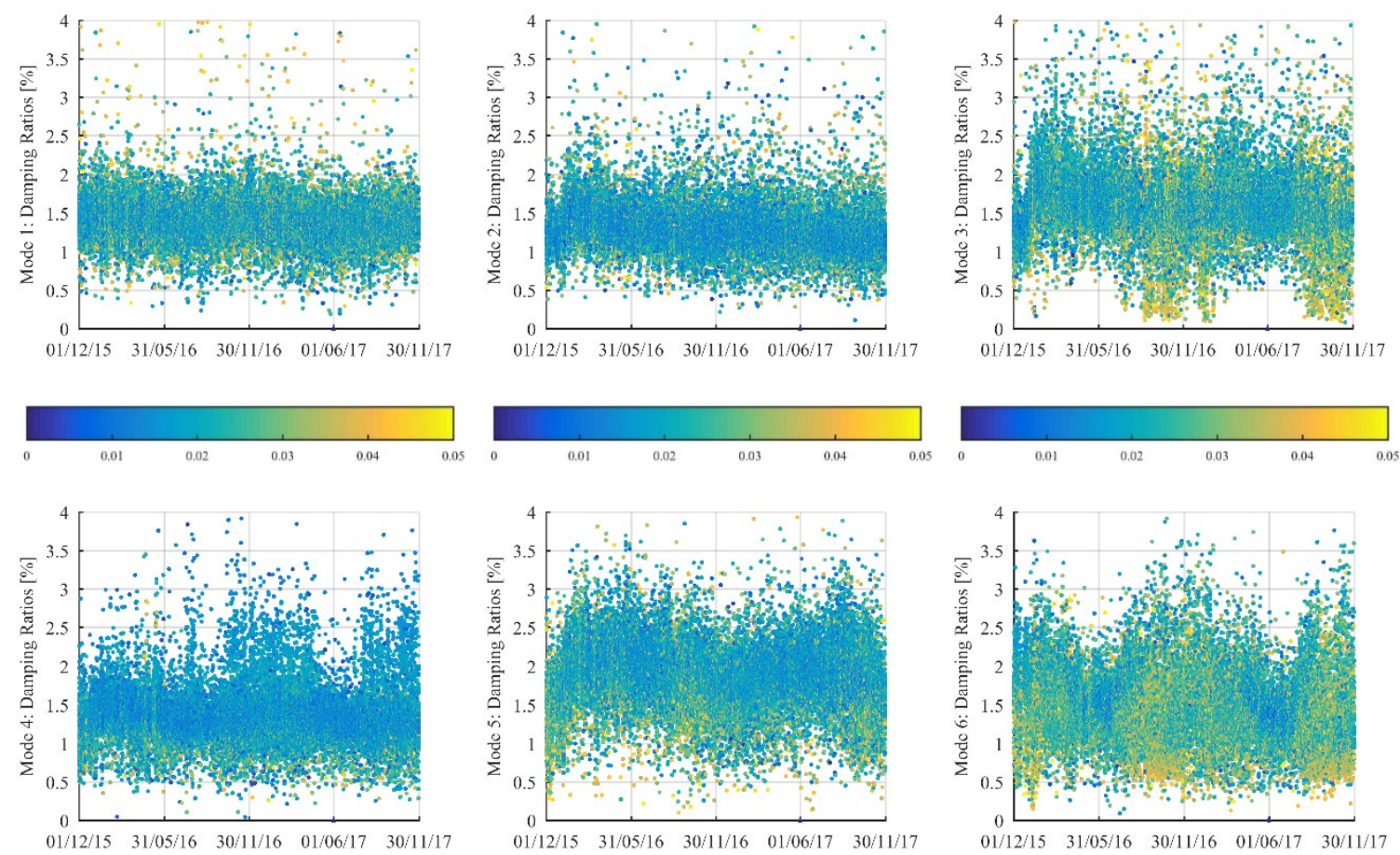

Figure 11 - Damping ratios with colour as a function of the coefficients of variation (Processing C). 
Finally, the results obtained with Processings A and C, the first and last ones, are summarized in Table 3 for comparison. For each vibration mode, means and standard deviations of the estimates obtained for the entire analysed period were calculated for four parameters: natural frequencies (mean (f) and std (f)), damping ratios (mean $(d)$ and std $(d))$, frequency standard deviations (mean $\left(f_{\text {std }}\right)$ and std $\left(f_{\text {std }}\right)$ ) and damping coefficient of variation $\left(\right.$ mean $\left(\mathrm{d}_{\mathrm{cv}}\right)$ and std $\left.\left(\mathrm{d}_{\mathrm{cv}}\right)\right)$. Additionally, the characteristics of Processings $\mathrm{A}, \mathrm{B}$ and $\mathrm{C}$ are presented in Table 4.

In the case of natural frequencies, the mean and standard deviation for the whole studied period did not present considerable changes from Processing A to $\mathrm{C}$, which was expected, since the effect of operational and environmental conditions on natural frequencies is predominant when compared to the effect of random errors. The elimination of estimates associated with the turbine frequency, however, led to a decrease of the third mode natural frequency mean. On the other hand, the mean and standard deviation of frequency standard deviations decreased substantially for the six modes, indicating a more accurate set of estimates.

Considerable variations were observed in the means of the damping ratios of the third, fourth and six modes. The third mode damping ratio mean for the studied period increased in agreement with the elimination of turbine rotation generated poles, and the fourth mode damping ratio mean decreased in agreement with the elimination of outliers with high uncertainty, which presented high damping values. Estimates that are more accurate were achieved also in the case of damping ratios, as shown by the clear reduction in the values of damping coefficients of variation.

Table 3 - Results comparison between Processing A and C

\begin{tabular}{lcccccccc}
\hline Processing & $\begin{array}{c}\text { mean }(\mathrm{f}) \\
{[\mathrm{Hz}]}\end{array}$ & $\begin{array}{c}\mathrm{std}(\mathrm{f}) \\
{[\mathrm{Hz}]}\end{array}$ & $\begin{array}{c}\text { mean }(\mathrm{d}) \\
{[\%]}\end{array}$ & $\begin{array}{c}\mathrm{std}(\mathrm{d}) \\
{[\%]}\end{array}$ & $\begin{array}{c}\text { mean }\left(\mathrm{f}_{\mathrm{std}}\right) \\
{[\mathrm{Hz}]}\end{array}$ & $\begin{array}{c}\text { std }\left(\mathrm{f}_{\text {std }}\right) \\
{[\mathrm{Hz}]}\end{array}$ & $\begin{array}{c}\text { mean }\left(\mathrm{d}_{\mathrm{cv}}\right) \\
{[\%]}\end{array}$ & $\begin{array}{c}\text { std }\left(\mathrm{d}_{\mathrm{cv}}\right) \\
{[\%]}\end{array}$ \\
\hline Mode 1-A & 2.523 & 0.117 & 1.445 & 0.598 & 0.013 & 0.019 & 36.3 & 56.7 \\
Mode 1 - C & 2.524 & 0.116 & 1.414 & 0.409 & 0.008 & 0.005 & 20.8 & 7.5 \\
\hline Mode 2 - A & 2.670 & 0.121 & 1.284 & 0.298 & 0.011 & 0.014 & 34.4 & 47.2 \\
Mode 2 - C & 2.670 & 0.121 & 1.289 & 0.294 & 0.007 & 0.004 & 17.9 & 6.9 \\
\hline Mode 3 - A & 3.495 & 0.165 & 1.504 & 0.483 & 0.029 & 0.033 & 76.8 & 105.5 \\
Mode 3 - C & 3.492 & 0.169 & 1.592 & 0.444 & 0.014 & 0.007 & 22.5 & 8.5 \\
\hline Mode 4-A & 4.108 & 0.190 & 1.390 & 0.442 & 0.023 & 0.025 & 44.4 & 66.6 \\
Mode 4-C & 4.109 & 0.191 & 1.334 & 0.334 & 0.010 & 0.005 & 16.7 & 5.6 \\
\hline Mode 5 - A & 4.995 & 0.231 & 1.846 & 0.489 & 0.045 & 0.051 & 58.1 & 92.6 \\
Mode 5 - C & 4.994 & 0.231 & 1.874 & 0.430 & 0.019 & 0.008 & 20.4 & 7.5 \\
\hline Mode 6 - A & 5.668 & 0.293 & 1.375 & 0.564 & 0.043 & 0.034 & 64.1 & 55.4 \\
Mode 6 - C & 5.640 & 0.291 & 1.477 & 0.460 & 0.021 & 0.009 & 24.3 & 8.3 \\
\hline
\end{tabular}


Table 4 - Characteristics of Processings A, B and C

\begin{tabular}{|c|c|}
\hline Processing & Characteristics \\
\hline A & $\begin{array}{l}\text { Uncertainty of modal estimates quantified, but not included } \\
\text { in the tracking algorithm. }\end{array}$ \\
\hline B & $\begin{array}{l}\text { Elimination of poles with: } \\
\text { - } \quad \mathrm{f}_{\text {std }} \text { equal of higher than } 0.05 \mathrm{~Hz} \text {; } \\
\text { - } \mathrm{d}_{\mathrm{cv}} \text { equal or higher than } 50 \% \text {. }\end{array}$ \\
\hline $\mathrm{C}$ & $\begin{array}{l}\text { Elimination of poles with: } \\
\text { - } \mathrm{f}_{\text {std }} \text { equal of higher than } 0.05 \mathrm{~Hz} \text {; } \\
\text { - } \mathrm{d}_{\mathrm{cv}} \text { equal or higher than } 50 \% \text {; } \\
\text { - } \mathrm{f}_{\text {std }} \text { lower than } 0.005 \mathrm{~Hz} \text { in the range from } 3.566 \mathrm{~Hz} \\
\text { to } 3.576 \mathrm{~Hz} ; \\
\text { - } \mathrm{d}_{\text {std }} \text { higher than } 0.50 \% \text { in the range from } 3.90 \mathrm{~Hz} \text { to } \\
\quad 4.60 \mathrm{~Hz} \text {. }\end{array}$ \\
\hline
\end{tabular}

\section{Using uncertainties estimates on the minimization of environmental and operational effects on natural frequencies}

The modal properties of a structure, namely the values of natural frequencies, can be used as features for damage detection, based on the principle that significant damages, even if localized, will induce changes in the structures global dynamic behaviour, thus permanently changing the values of natural frequencies. However, to detect the changes in the dynamic behaviour of a structure due to eventual damages, it is necessary to remove from modal properties the changes due to the effect of the variations of environmental and operational conditions throughout the year, which can easily present higher intensities and thus camouflage the effects of damages.

It is important to understand which external variables affect the behaviour of a structure, in order to build models capable of mitigating their effects on modal properties. For instance, in the case of concrete dams, the variation of the reservoir water level is known to produce a major effect in the structures natural frequencies $[19,59]$.

In this sense, the values of the first natural frequency estimates were represented in Figure 12 versus the corresponding levels of the reservoir water level, as an example. The frequency estimates obtained with both Processing A (not using uncertainties) and Processing C (using uncertainties) were represented for comparison, on the left and right parts of Figure 12, respectively. Quadratic relations were found between the evolution of natural frequencies and reservoir water level, as it was expected. Though high determination coefficients were obtained using natural frequencies obtained either from Processing A and from Processing $\mathrm{C}$, a higher coefficient was obtained with the data resulting from Processing C (0.937) when compared with the one obtained with Processing A (0.907), confirming that the introduction of modal properties uncertainty in the tracking process had a positive effect in the removing of outliers. Considering this and the results presented in Table 3, the properties tracked with Processing C (using uncertainties) will be adopted to build regression models capable of mitigating the effect of external factors. 

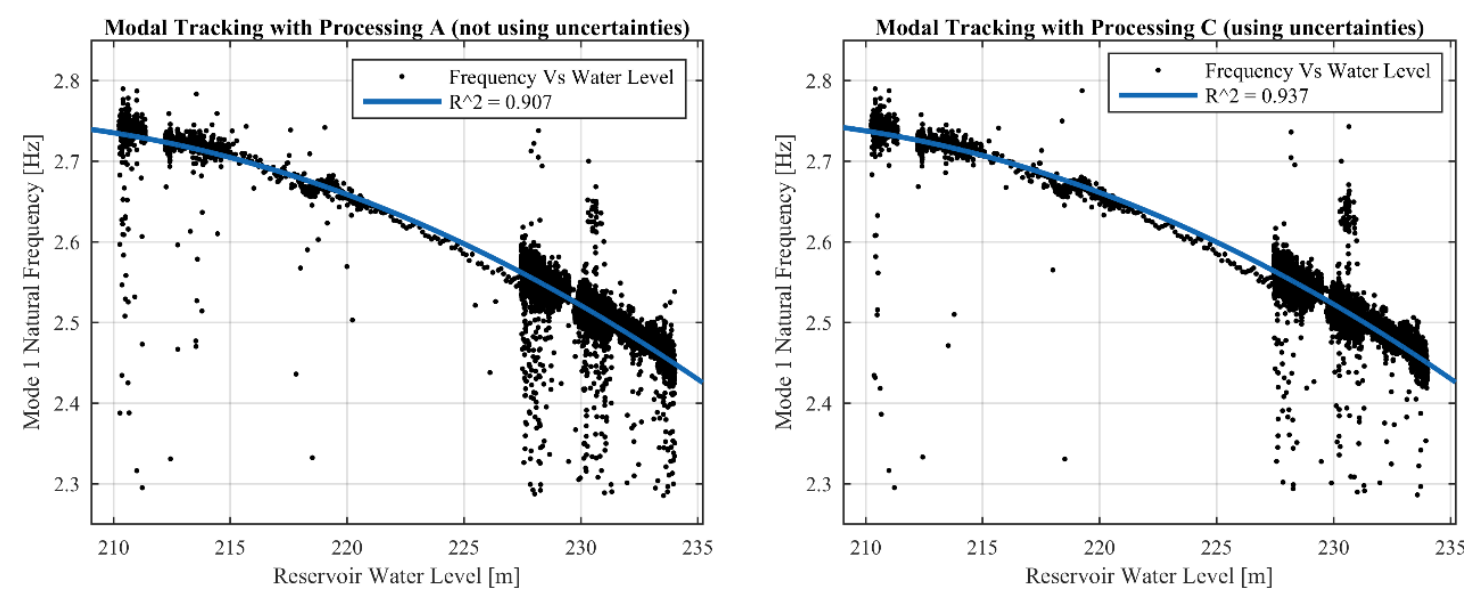

Figure 12 - Correlation between reservoir water level and the first natural frequency using Processing A (not using uncertainties) and Processing C (using uncertainties).

Multiple linear regression models are used. These models exploit the linear correlations between a dependent variable, in this case natural frequencies, and a set of $p$ independent variables known as predictors, which correspond to environmental and operational factors. The mathematical definition of a multiple linear regression model is provided by [60]:

$$
y=Z \cdot \beta+\varepsilon
$$

where $y$ is a vector that represents the dependent variable, $Z$ is a matrix that contains a first column of ones and $p$ independent variables (predictors) in the remaining $p$ columns, $\beta$ is a vector with weight parameters of the $p$ predictors and $\varepsilon$ is a vector with the values of the random error. Quantities contained in vector $\beta$ are estimated in a reference period by minimizing the norm of the prediction error, which corresponds to the difference between measured and predicted natural frequencies. Instead of a standard least-squares fit, a weighted fit can be computed assigning a weight to each data point, creating a model that gives lower importance to observations with higher uncertainty. For this, Matlab's function "fitlm" [57] was used, considering the option "Weights" [61].

Besides reservoir water level, also concrete temperature and concrete hardening play an important role in the evolution of modal properties, thus a multiple linear regression model was built to predict the values of natural frequencies considering these three variables, plus the values of ambient temperature, which was found to be an important predictor as well [62].

In the case of reservoir water level, since a linear model is being built but the relationship between the predictor and natural frequency has been shown to be quadratic, two variables were considered: the first corresponding to the values of water level and the second corresponding to the squared value of each water level observation. On the other hand, temperature-related variables such as ambient temperature and concrete temperature were used as predictors without any modification since the relationship between these variables and natural frequencies have been found to have a linear nature. Finally, the influence of concrete hardening on natural frequencies may assume a significant role in such a massive structure, especially during the first years after the last pouring, so it should not be neglected. To simulate this 
slow non-linear process, whose increase rate diminishes with time, a simple model is used considering a logarithmic function.

Six linear regression models were built considering each of the six modes natural frequencies as dependent variables and the five independent variables presented in Table 5 as predictors.

Table 5 - Variables used to build the regression models and to compute natural frequencies forecasts

\begin{tabular}{|c|c|c|c|c|c|}
\hline Dependent Variable [y] & & Natu & Frequencies & & \\
\hline Independent Variables [p] & Water levels & $\begin{array}{l}\text { Squared water } \\
\text { level values }\end{array}$ & $\begin{array}{c}\text { Ambient } \\
\text { Temperature }\end{array}$ & $\begin{array}{c}\text { Concrete } \\
\text { Temperature }\end{array}$ & $\begin{array}{l}\text { Concrete } \\
\text { Hardening }\end{array}$ \\
\hline
\end{tabular}

Natural frequencies obtained for the six vibration modes between 01/12/2015 and 30/11/2016, using Processing $\mathrm{C}$, were used to build the regression models, while the frequencies obtained for the period between 01/12/2016 and 30/11/2017 can be used for comparison with predictions provided by the models. An example regarding the natural frequency evolution of the first vibration mode is presented in Figure 13, where experimental data and predictions obtained from the regression model are presented, respectively in blue and red. The two parts of Figure 13 may seem to be representing exactly the same pair of entities, since they both show experimental data and predictions, nevertheless, there is a fundamental difference between the two. While the first year of predictions was achieved through a model built with data from the same period (20152016), the second year of predictions (2016-2017) rely on the same model, which was built with data from the previous year, and is then fed with predictors (water level, concrete temperature, etc) from the second year. More details on the regression model used are presented in [63].

Good correlations were achieved between experimental and predicted estimates, for most modes, with the first four correlations presenting determination coefficients above 0.80 . However, with the aim of improving the results, the models were tested once again, this time considering the uncertainty associated with each natural frequency estimate as weights. The weights were considered as the inverse of the variance associated with each frequency estimate, thus as the uncertainty decreases, the weight of each estimate increases. The coefficients of determination obtained for each mode with each model are presented in Table 6 for both the training and prediction periods. The values of determination coefficients that correspond to improvements from the results previously obtained with regular models were highlighted with blue, while dark orange was used for cases where the determination coefficient decreased. Generally, similar results were obtained with both models, with only slight improvements being achieved for the first, fourth and six modes. It should be noted that the improvement is not very significant because the points with higher uncertainty have already been eliminated in the tracking process. 

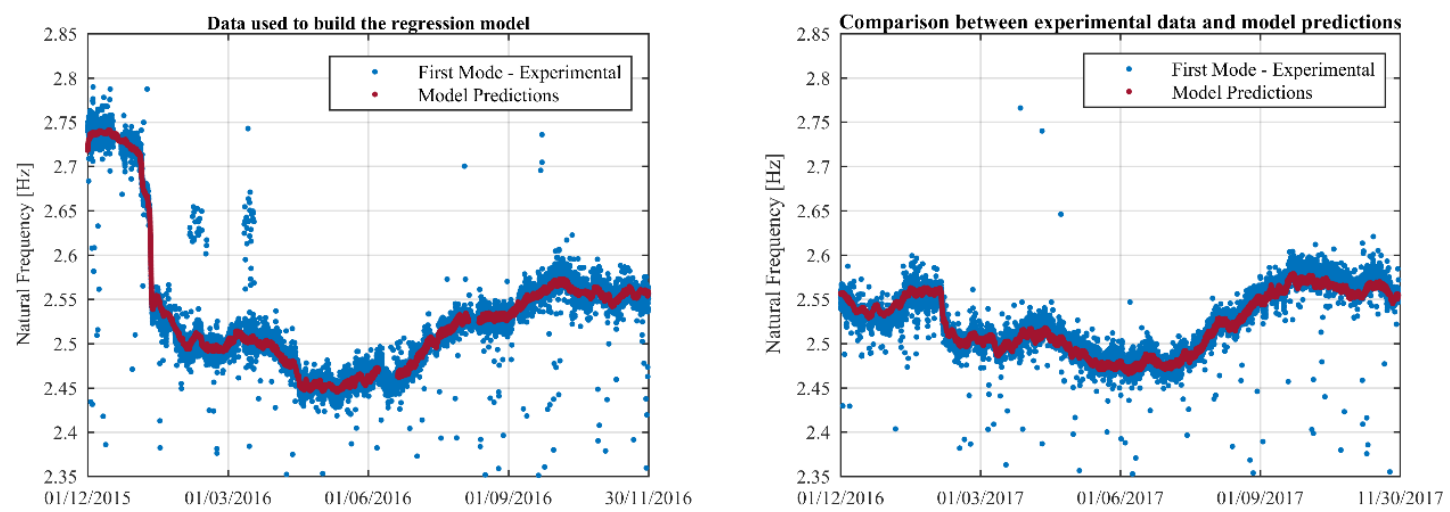

Figure 13 - First natural frequency: experimental values and predictions from multiple linear regression model.

Table 6 - Coefficients of determination for regular and weighted regression models

\begin{tabular}{ccccc}
\hline & \multicolumn{2}{c}{ Training Period } & \multicolumn{2}{c}{ Prediction Period } \\
\hline Frequency & $\begin{array}{c}\text { Regular Model } \\
\mathrm{R}^{2}\end{array}$ & $\begin{array}{c}\text { Weighted Model } \\
\mathrm{R}^{2}\end{array}$ & $\begin{array}{c}\text { Regular Model } \\
\mathrm{R}^{2}\end{array}$ & $\begin{array}{c}\text { Weighted Model } \\
\mathrm{R}^{2}\end{array}$ \\
\hline F1 & 0.943 & 0.943 & 0.857 & 0.859 \\
F2 & 0.986 & 0.986 & 0.931 & 0.930 \\
F3 & 0.965 & 0.965 & 0.827 & 0.827 \\
F4 & 0.974 & 0.974 & 0.863 & 0.866 \\
F5 & 0.923 & 0.923 & 0.792 & 0.792 \\
F6 & 0.887 & 0.888 & 0.519 & 0.539 \\
\hline
\end{tabular}

\section{Conclusions}

Baixo Sabor arch dam and the dynamic monitoring system installed in the structure were introduced. The time-series of accelerations obtained during the first two years of dynamic monitoring were used to study the importance of considering the uncertainties of modal properties during the several processing stages of vibration-based structural health monitoring.

First, the modal identification of the structure was achieved using data recorded during the first day of monitoring, with the aim of obtaining reference parameters to execute automatic modal tracking. To perform the identification, a version of SSI-Cov was used that allows the quantification of the uncertainty associated with the modal parameters estimates. Therefore, natural frequencies and damping ratios (with respective standard deviations) were obtained for the six vibration modes identified, as well as mode shapes. Furthermore, it was noted that the values of uncertainties associated with modal properties might vary significantly from mode to mode and, as expected, that damping ratios estimates present considerably higher uncertainties than those of natural frequencies.

Then automated operational modal analysis was performed to the two years of data recorded by the continuous dynamic monitoring, which was used to track the modal properties of the six vibration modes 
identified. The tracking was based on the application of SSI-Cov method, an algorithm using cluster analysis and on the comparison between modal estimates and reference values. It was observed that several frequency and damping estimates presented high standard deviation values, which should not be accepted, and that many of them correspond to outliers. In this context, the effect of the consideration of uncertainties within the tracking algorithm was tested, in order to minimize the number of outliers and increase the confidence level of modal estimates. The intended purpose was accomplished and good results were achieved with this processing, that is, the standard deviation of both natural frequencies and damping ratios estimates was considerably decreased for the six studied modes, and many outliers corresponding to misidentifications were eliminated.

Additionally, the consideration of the uncertainty of modal estimates in the tracking algorithm revealed to be adequate to remove as well the presence of parasite frequencies from tracked data, namely the influence of the rotation frequency of the turbines in the hydroelectric development, which was achieved through the elimination of poles with very low standard deviations.

It was observed that the elimination of frequency estimates with high uncertainty led to sets of frequency values that correlate better with the environmental and operational factors, more specifically with the reservoir water level. Finally, the uncertainties associated with natural frequency estimates were considered as weights in the building of multiple regression models, within an attempt to increase the ability of these models to predict natural frequencies. However, it was verified that only minor gains can be achieved with this procedure since about half the regression models presented correlation coefficients similar to those obtained before the introduction of weights, while the other half presented very slight improvements.

In short, the quantification of uncertainties demonstrated to be a useful tool for the accurate identification and tracking of modal properties estimates, adding information about the structural system under analysis and allowing to better characterize its evolution over time.

\section{Acknowledgements}

This work was financially supported by: Projects POCI-01-0145-FEDER-007457 - CONSTRUCT - Institute of R\&D In Structures and Construction and PTDC/ECM-EST/0805/2014|16761 - DAM_AGE - Advanced Online Dynamic Structural Health Monitoring of Concrete Dams, funded by FEDER funds through COMPETE2020 - Programa Operacional Competitividade e Internacionalização (POCI) - and by national funds through FCT - Fundação para a Ciência e a Tecnologia; FCT PhD Scholarship SFRH/BD/100587/2014 provided to the first author. The authors would like also to acknowledge all the collaboration and support provided by EDP Produção.

\section{References}

1. Cunha, Á., E. Caetano, F. Magalhães, and C. Moutinho, Dynamic identification and continuous dynamic monitoring of bridges: different applications along bridges life cycle. Structure and Infrastructure Engineering, 2018. 14(4): p. 445-467. 
2. Salawu, O.S. and C. Williams, Bridge assessment using forced-vibration testing. Journal of Structural Engineering (United States), 1995. 121(2): p. 161-173.

3. Brownjohn, J.M.W., Structural health monitoring of civil infrastructure. Philosophical Transactions of the Royal Society A: Mathematical, Physical and Engineering Sciences, 2007. 365(1851): p. 589-622.

4. Farrar, C.R. and K. Worden, An Introduction to Structural Health Monitoring, in New Trends in Vibration Based Structural Health Monitoring, A. Deraemaeker and K. Worden, Editors. 2010, Springer Vienna: Vienna. p. 1-17.

5. Santos, J.P., Smart Structural Health Monitoring Techniques for Novelty Identification in Civil Engineering Structures. 2014, IST - University of Lisbon.

6. Caetano, E., Á. Cunha, F. Magalhães, and C. Moutinho, Studies for controlling humaninduced vibration of the Pedro e Inês footbridge, Portugal. Part 1: Assessment of dynamic behaviour. Engineering Structures, 2010. 32(4): p. 1069-1081.

7. Caetano, E., Á. Cunha, C. Moutinho, and F. Magalhães, Studies for controlling humaninduced vibration of the Pedro e Inês footbridge, Portugal. Part 2: Implementation of tuned mass dampers. Engineering Structures, 2010. 32(4): p. 1082-1091.

8. Magalhães, F., A. Cunha, and E. Caetano, Vibration based structural health monitoring of an arch bridge: From automated OMA to damage detection. Mechanical Systems and Signal Processing, 2012. 28: p. 212-228.

9. Hu, W.H., E. Caetano, and T. Cunha, Structural health monitoring of a stress-ribbon footbridge. Engineering Structures, 2013. 57: p. 578-593.

10. Cabboi, A., F. Magalhães, C. Gentile, and Á. Cunha, Automated modal identification and tracking: Application to an iron arch bridge. Structural Control and Health Monitoring, 2017. 24(1).

11. Kvåle, K.A. and O. Øiseth, Structural monitoring of an end-supported pontoon bridge. Marine Structures, 2017. 52: p. 188-207.

12. Devriendt, C., F. Magalhães, W. Weijtjens, G. De Sitter, Á. Cunha, and P. Guillaume, Structural health monitoring of offshore wind turbines using automated operational modal analysis. Structural Health Monitoring, 2014. 13(6): p. 644-659.

13. Oliveira, G., F. Magalhães, Á. Cunha, and E. Caetano, Development and implementation of a continuous dynamic monitoring system in a wind turbine. Journal of Civil Structural Health Monitoring, 2016. 6(3): p. 343-353.

14. Hu, W.H., D.H. Tang, M. Wang, J.L. Liu, Z.H. Li, W. Lu, J. Teng, S. Said, and R.G. Rohrmann, Resonance monitoring of a horizontal wind turbine by strain-based automated operational modal analysis. Energies, 2020. 13(3).

15. Martins, N., E. Caetano, S. Diord, F. Magalhães, and T. Cunha, Dynamic monitoring of a stadium suspension roof: Wind and temperature influence on modal parameters and structural response. Engineering Structures, 2014. 59: p. 80-94.

16. Ramos, L.F., L. Marques, P.B. Lourenço, G. De Roeck, A. Campos-Costa, and J. Roque, Monitoring historical masonry structures with operational modal analysis: Two case studies. Mechanical Systems and Signal Processing, 2010. 24(5): p. 1291-1305.

17. Gentile, C., M. Guidobaldi, and A. Saisi, One-year dynamic monitoring of a historic tower: damage detection under changing environment. Meccanica, 2016. 51(11): p. 2873-2889. 
18. Ubertini, F., G. Comanducci, and N. Cavalagli, Vibration-based structural health monitoring of a historic bell-tower using output-only measurements and multivariate statistical analysis. Structural Health Monitoring, 2016. 15(4): p. 438-457.

19. Darbre, G.R. and J. Proulx, Continuos ambient-vibration monitoring of the arch dam of Mauvoisin. Earthquake Engineering and Structural Dynamics, 2002. 31(2): p. 475-480.

20. Mendes, P., Observação e Análise do Comportamento Dinâmico de Barragens de Betão. 2010, Faculdade de Engenharia da Universidade do Porto. Portuguese.

21. Pereira, S., F. Magalhães, J.P. Gomes, Á. Cunha, and J.V. Lemos, Dynamic monitoring of a concrete arch dam during the first filling of the reservoir. Engineering Structures, 2018. 174: p. 548-560.

22. Ewins, D.J., Modal Testing: Theory, Practice and Application. 2000, Baldock, England: Research Studies Press Ltd.

23. Heylen, W., S. Lammens, and P. Sas, Modal Analysis Theory and Testing. 2007, Katholieke Universiteit Leuven, Belgium.

24. Maia, N. and J. Silva, Theoretical and Experimental Modal Analysis. 1997: Research Studies Press Ltd.

25. Verboven, P., E. Parloo, P. Guillaume, and M. Van Overmeire, Autonomous structural health monitoring - Part I: Modal parameter estimation and tracking. Mechanical Systems and Signal Processing, 2002. 16(4): p. 637-657.

26. Rainieri, C., G. Fabbrocino, and E. Cosenza, Near real-time tracking of dynamic properties for standalone structural health monitoring systems. Mechanical Systems and Signal Processing, 2011. 25(8): p. 3010-3026.

27. Zabel, V., Operational modal analysis - Theory and aspects of application in civil engineering. 2019, Bauhaus-Universitat Weimar.

28. Brincker, R., L. Zhang, and P. Andersen. Modal Identification from Ambient Responses using Frequency Domain Decomposition. in IMAC 18, International Modal Analysis Conference. 2000. San Antonio, USA.

29. Overschee, P.V. and B.D. Moor, Subspace Identification for Linear Systems - Theory, Implementation, Applications. 1996: Kluwer Academic Publishers.

30. Peeters, B. and H. Van der Auweraer, PolyMax: a Revolution in Operational Modal Analysis, in IOMAC, International Operational Modal Analysis Conference. 2005: Copenhagen, Denmark.

31. Reynders, E., System Identification Methods for (Operational) Modal Analysis: Review and Comparison. Archives of Computational Methods in Engineering, 2012. 19(1): p. 51-124.

32. Reynders, E., R. Pintelon, and G. De Roeck, Uncertainty bounds on modal parameters obtained from stochastic subspace identification. Mechanical Systems and Signal Processing, 2008. 22(4): p. 948-969.

33. Peeters, B. and G. De Roeck, REFERENCE-BASED STOCHASTIC SUBSPACE IDENTIFICATION FOR OUTPUT-ONLY MODAL ANALYSIS. Mechanical Systems and Signal Processing, 1999. 13(6): p. 855-878.

34. Magalhães, F. and A. Cunha, Explaining operational modal analysis with data from an arch bridge. Mechanical Systems and Signal Processing, 2011. 25(5): p. 1431-1450. 
35. Cara, F.J., J. Juan, E. Alarcón, E. Reynders, and G. De Roeck, Modal contribution and state space order selection in operational modal analysis. Mechanical Systems and Signal Processing, 2013. 38(2): p. 276-298.

36. Mrabet, E., M. Abdelghani, and N. Ben Kahla, A New Criterion for the Stabilization Diagram Used with Stochastic Subspace Identification Methods: An Application to an Aircraft Skeleton. Shock and Vibration, 2014. 2014: p. 409298.

37. Olsen, P., M.O. Juul, M. Tarpo, and R. Brincker. Stabilization diagrams using operationalmodal analysis and sliding filters. in IOMAC 2017 - 7th International Operational Modal Analysis Conference. 2017.

38. Marrongelli, G. and C. Gentile. Development and application of automated OMA algorithms. in 8th IOMAC - International Operational Modal Analysis Conference, Proceedings. 2019.

39. Nord, T.S., Ø.W. Petersen, and H. Hendrikse, Stochastic subspace identification of modal parameters during ice-structure interaction. Philosophical Transactions of the Royal Society A: Mathematical, Physical and Engineering Sciences, 2019. 377(2155).

40. Döhler, M. and L. Mevel, Efficient multi-order uncertainty computation for stochastic subspace identification. Mechanical Systems and Signal Processing, 2013. 38(2): p. 346366.

41. Döhler, M., X.-B. Lam, and L. Mevel, Uncertainty quantification for modal parameters from stochastic subspace identification on multi-setup measurements. Mechanical Systems and Signal Processing, 2013. 36(2): p. 562-581.

42. Reynders, E., K. Maes, G. Lombaert, and G. De Roeck, Uncertainty quantification in operational modal analysis with stochastic subspace identification: Validation and applications. Mechanical Systems and Signal Processing, 2016. 66-67: p. 13-30.

43. Pintelon, R., P. Guillaume, and J. Schoukens, Uncertainty calculation in (operational) modal analysis. Mechanical Systems and Signal Processing, 2007. 21(6): p. 2359-2373.

44. De Troyer, T., P. Guillaume, R. Pintelon, and S. Vanlanduit, Fast calculation of confidence intervals on parameter estimates of least-squares frequency-domain estimators. Mechanical Systems and Signal Processing, 2009. 23(2): p. 261-273.

45. El-kafafy, M., G. Accardo, B. Peeters, K. Janssens, T. De Troyer, and P. Guillaume. A fast maximum likelihood-based estimation of a modal model. in Conference Proceedings of the Society for Experimental Mechanics Series. 2015.

46. Diord, S., F. Magalhães, Á. Cunha, and E. Caetano, High spatial resolution modal identification of a stadium suspension roof: Assessment of the estimates uncertainty and of modal contributions. Engineering Structures, 2017. 135: p. 117-135.

47. Carden, E.P. and A. Mita, Challenges in developing confidence intervals on modal parameters estimated for large civil infrastructure with stochastic subspace identification. Structural Control and Health Monitoring, 2011. 18(1): p. 53-78.

48. Tondreau, G. and A. Deraemaeker, Numerical and experimental analysis of uncertainty on modal parameters estimated with the stochastic subspace method. Journal of Sound and Vibration, 2014. 333(18): p. 4376-4401.

49. Au, S.-K., Uncertainty law in ambient modal identification-Part I: Theory. Mechanical Systems and Signal Processing, 2014. 48(1): p. 15-33.

50. Au, S.-K., Uncertainty law in ambient modal identification---Part II: Implication and field verification. Mechanical Systems and Signal Processing, 2014. 48(1): p. 34-48. 
51. Yan, W.-J., C. Papadimitriou, L.S. Katafygiotis, and D. Chronopoulos, An analytical perspective on Bayesian uncertainty quantification and propagation in mode shape assembly. Mechanical Systems and Signal Processing, 2020. 135: p. 106376.

52. Magalhães, F., A. Cunha, and E. Caetano, Online automatic identification of the modal parameters of a long span arch bridge. Mechanical Systems and Signal Processing, 2009. 23(2): p. 316-329.

53. Allemang, R.J., The modal assurance criterion-twenty years of use and abuse. Sound and vibration, 2003. 37(8): p. 14-23.

54. Gomes, J.P. and J.V. Lemos, Characterization of the dynamic behaviour of a concrete arch dam by means of forced vibration tests and numerical models. Earthquake Engineering and Structural Dynamics, 2020. 49(7): p. 679-694.

55. Magalhães, F., S. Amador, Á. Cunha, and E. Caetano. DynaMo - Software for vibration based structural health monitoring. in Bridge Maintenance, Safety, Management, Resilience and Sustainability - Proceedings of the Sixth International Conference on Bridge Maintenance, Safety and Management. 2012.

56. EDP, E.d.P. 23/01/2017]; Available from: http://www.a-nossaenergia.edp.pt/centros_produtores/.

57. Mathworks, Matlab. R2016a. 2016.

58. Pereira, S., F. Magalhães, and Á. Cunha. Modal identification of concrete dams with different typologies under natural excitation. in 8th IOMAC - International Operational Modal Analysis Conference, Proceedings. 2019.

59. Mendes, P. and S. Oliveira. Study of dam-reservoir dynamic interaction using vibration tests on a physical model. in Proceedings of the 2nd International Operational Modal Analysis Conference, IOMAC 2007. 2007.

60. Johnson, R.A. and D.W. Wichern, Applied Multivariate Statistical Analysis. 6th ed, ed. P. Hall. 2007.

61. Strutz, T., Data Fitting and Uncertainty (A practical introduction to weighted least squares and beyond). 2010 .

62. Pereira, S., F. Magalhães, A. Cunha, J. Gomes, and J.V. Lemos. Installation and results from the first 18 months of operation of the dynamic monitoring system of Baixo Sabor arch dam. in Life-Cycle Analysis and Assessment in Civil Engineering: Towards an Integrated Vision - Proceedings of the 6th International Symposium on Life-Cycle Civil Engineering, IALCCE 2018. 2019.

63. Pereira, S., Structural Condition Assessment of Dams Based on Continuous Dynamic Monitoring. 2019, Faculty of Engineering of University of Porto: Porto. English. 